This is a self-archived version of an original article. This version may differ from the original in pagination and typographic details.

Author(s): Kuosmanen, Riikka; Puttreddy, Rakesh; Rissanen, Kari; Sievänen, Elina

Title: Systematic Modulation of the Supramolecular Gelation Properties of Bile Acid Alkyl Amides

Year: 2018

Version: Accepted version (Final draft)

Copyright: @ 2018 Wiley-VCH Verlag GmbH \& Co. KGaA

Rights: In Copyright

Rights url: http://rightsstatements.org/page/InC/1.0/?language=en

Please cite the original version:

Kuosmanen, R., Puttreddy, R., Rissanen, K., \& Sievänen, E. (2018). Systematic Modulation of the Supramolecular Gelation Properties of Bile Acid Alkyl Amides. Chemistry: A European Journal, 24(70), 18676-18681. https://doi.org/10.1002/chem.201803151 


\section{CHEMISTRY A European Journal}

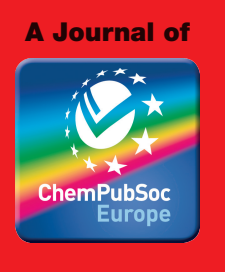

\section{Accepted Article}

Title: Systematic Modulation of the Supramolecular Gelation Properties of Bile Acid Alkyl Amides

Authors: Riikka Kuosmanen, Rakesh Puttreddy, Elina Sievänen, and Kari Rissanen

This manuscript has been accepted after peer review and appears as an Accepted Article online prior to editing, proofing, and formal publication of the final Version of Record (VoR). This work is currently citable by using the Digital Object Identifier (DOI) given below. The VoR will be published online in Early View as soon as possible and may be different to this Accepted Article as a result of editing. Readers should obtain the VoR from the journal website shown below when it is published to ensure accuracy of information. The authors are responsible for the content of this Accepted Article.

To be cited as: Chem. Eur. J. 10.1002/chem.201803151

Link to VoR: http://dx.doi.org/10.1002/chem.201803151 


\title{
Systematic Modulation of the Supramolecular Gelation Properties of Bile Acid Alkyl Amides
}

\author{
Riikka Kuosmanen, ${ }^{[a]}$ Rakesh Puttreddy, ${ }^{[a]}$ Kari Rissanen ${ }^{*[a]}$ and Elina Sievänen*[a]
}

\begin{abstract}
The self-assembly properties of nine bile acid alkyl amidebased low-molecular weight gelators (LMWGs) are studied in detail. Based on the results the number of hydroxyl groups attached to the steroidal backbone plays a major role in the gelation, although the nature of the aliphatic side chain modulates the gelation abilities as well. Of the $50 \mathrm{gel}$ systems studied, 35 are based on lithocholic acid and 15 on cholic acid derivatives. The deoxycholic acid derivatives did not form any gels. The gelation commences primarily in aromatic solvents and the gels manifest typical fibrous or spherical morphologies. The ${ }^{13} \mathrm{C}$ CPMAS NMR spectra measured from the crystalline materials and the corresponding wet organogels are analogous, suggesting that the chemical environments viz. the intermolecular interactions found in the organogels and in the crystalline state are similar. The single crystal X-ray structures of all nine bile acid amide derivatives studied revealed very similar molecular conformations in the solid state and gave insights into the possible intermolecular interactions in the gel state.
\end{abstract}

\section{Introduction}

Supramolecular gels formed by low molecular weight gelators (LMWGs) have been under intensive research in the past decades. ${ }^{1-3}$ The properties of these soft systems differ from those of pure solids or liquids leading to emergence of applications in numerous fields, such as sensing, ${ }^{4}$ biomedicine,${ }^{5}$ or materials technology. ${ }^{6}$ Some of the recent examples include the use of supramolecular ionogels in non-covalent antibacterial coatings ${ }^{7}$, in environmental remediation ${ }^{8}$, and as radical scavengers ${ }^{9}$. Supramolecular gels manifest a network consisting of fibers or other nano- or microstructures, which immobilizes the bulk solvent by weak interactions, such as hydrogen bonding, $\pi-\pi$ interactions, metal ion coordination, or van der Waals forces. ${ }^{1,2}$ Some gel materials exhibit crystalline character, and the organization of the gelator in the crystalline state of the gel fiber can provide a concrete way of linking aspects of these two extremes. This lays the foundation for trying to understand how changes in the molecular structure affect the properties of the formed gels. ${ }^{10-22}$

Bile acids are end products of cholesterol metabolism formed in the liver enhancing the digestion and absorption of lipids

[a] M.Sc. Riikka Kuosmanen, Dr. Rakesh Puttreddy, Prof. Kari Rissanen, Dr. Elina Sievänen

University of Jyvaskyla Department of Chemistry, Nanoscience Center, P.O. Box 35, 40014 Jyvaskyla, FINLAND

E-mail: kari.t.rissanen@iyu.fi, elina.i.sievanen@iyu.fi

Electronic Supporting Information for this article is given via a link at the end of the document. and lipid-soluble vitamins. They are of pharmacological interest, being potential carriers and enhancers of absorption of drugs as well as major regulators of cholesterol homeostasis. ${ }^{23-24}$ Bile acids possess a unique structure with a convex hydrophobic $\beta$ side, a concave hydrophilic $\alpha$-side, and a polar side chain. ${ }^{25}$ Because the molecule is polar on one side and apolar on the other, it is facially amphiphilic and its aggregates in water differ from those of classical surfactants. ${ }^{26}$ Since the difference in the steric crowding enables derivatization of each hydroxyl group attached to the steroidal backbone individually, the water/lipidsolubility of the molecules can be easily tailored. More convertibility is achieved by modifying the side chain of bile acids. ${ }^{27-28}$

Several bile acid amide derivatives containing a functional group at the end of the aliphatic side chain have been reported and their properties studied by us. ${ }^{29-36}$ Many of them have shown to be effective gelators, and one even formed stimuli-responsive metallogels. ${ }^{34}$ Recently, we have focused on the bile acid derivatives that have no functional group at the end of the aliphatic side chain. The aim has been to determine the role of the functional group in self-assembly properties. Within the group of bile acid ethyl amides, the lithocholic acid derivative was shown to form hydrogels in addition to organogels. ${ }^{37}$

In the current study, the self-assembly and gelation properties of nine bile acid alkyl amides were studied in detail. Careful control of the crystallization under equal conditions resulted in good quality single crystals of all nine amides. The subsequent single crystal $\mathrm{X}$-ray studies showed that the $\mathrm{N} \cdots \mathrm{H}$, $\mathrm{O} \cdots \mathrm{H}$, and $\mathrm{H} \cdots \mathrm{H}$ interactions were the most important intermolecular interactions affecting organization of the molecules in the solid state. Of the 50 gel systems formed, 35 consisted of lithocholic acid (LCA) derivatives and 15 of cholic acid (CA) derivatives, whereas deoxycholic acid (DCA) derivatives did not form any gels. Even though the length and branching of the aliphatic side chain clearly have an effect on the gelation abilities of the compounds, the number of hydroxyl groups attached to the steroidal backbone plays a major role in the gelation. The ${ }^{13} \mathrm{C}$ CPMAS NMR spectra measured from both the crystalline material and the corresponding wet gels are analogous, suggesting that the chemical environments viz. the intermolecular interactions found in the gel and in the crystalline state are similar.

\section{Results and Discussion}

\section{Synthesis}

LCA, DCA, and CA amides LCA1-CA9 were synthesized by following straightforward and facile literature methods (Scheme 
1). ${ }^{29-30,32-34,37-38}$ All compounds were purified by simple recrystallizations with yields varying between $32 \%$ and $73 \%$ (See Electronic Supporting Information for more details).

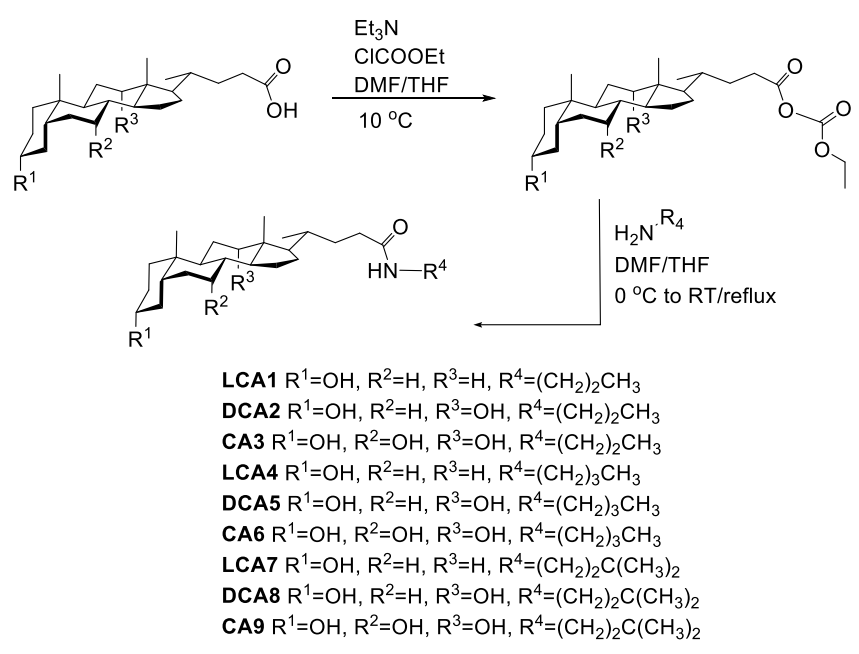

Scheme 1. The synthetic route leading to compounds LCA1-CA9

\section{Single Crystal X-ray Analysis}

Single crystals of compounds LCA1-CA9 suitable for X-ray diffraction analysis were obtained by slow evaporation of either acetonitrile, DMF, or ethyl acetate solutions. The compounds create a pseudo isomorphous and isostructural series, crystallizing in the monoclinic space group $P 2_{1}$ without solvent molecules (Figures 1 and 2). This differs markedly from the behavior of bile acid derivatives with shorter alkyl (ethyl) chains, where solvent molecules have a key role in stabilizing the crystal lattice. ${ }^{37}$ This suggests that for the compounds LCA1-CA9 with longer alkyl side chains the intermolecular bile acid-to-bile acid interactions are preferred over the bile acid-solvent interactions. The hydroxyl and amide groups are fully utilized in forming the intermolecular $\mathrm{O}-\mathrm{H} \cdots \mathrm{O}$ and $\mathrm{N}-\mathrm{H} \cdots \mathrm{O}$ hydrogen bonds to give a typical ordered 1-D bilayered structure (Figure S7). ${ }^{39-41}$ The Hirshfeld surface analysis ${ }^{42-45}$ for crystal structures of compounds LCA1-CA9 indicates that these bilayers form a compact 3-D crystal lattice by high percentage of $\mathrm{H}^{\cdots} \mathrm{H}$ interactions (Table S6 and Figures S9-S17).

\section{Gelation Properties}

The gelation abilities of compounds LCA1-CA9 were tested in 36 solvents and of compounds LCA1-CA6 additionally in 12 aqueous solutions. The results obtained are presented in Electronic Supporting Information (Tables S1-S3), while only selected gelation experiments are shown in Table 1. A total of 50 gel systems were formed, of which 35 by LCA and 15 by CA derivatives, respectively. In accordance with our previous results, DCA derivatives did not form any gels. Gel formation is mostly fa- (a)

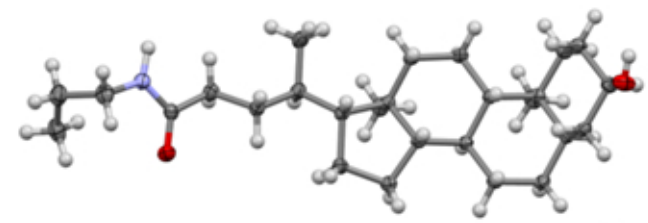

(b)

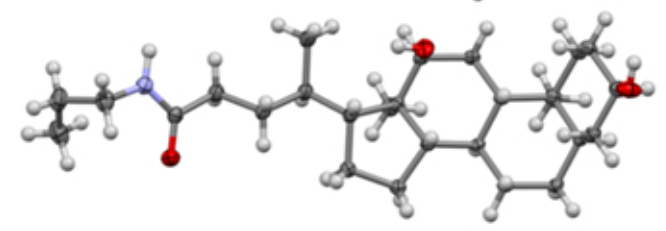

(c)

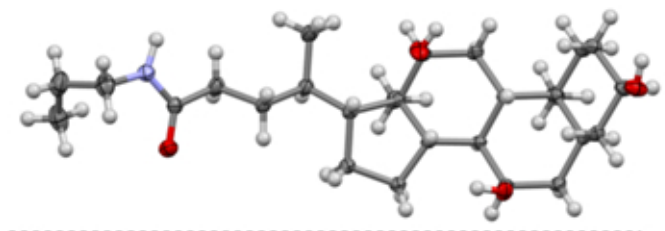

(d)

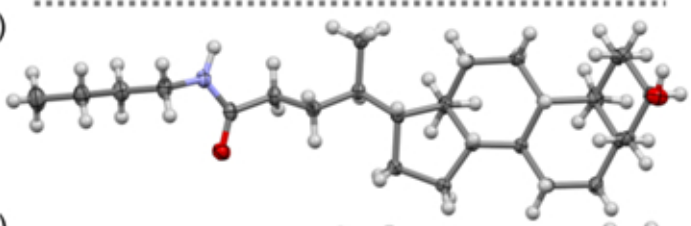

(e)

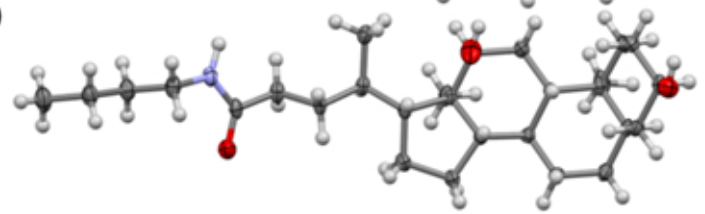

(f)

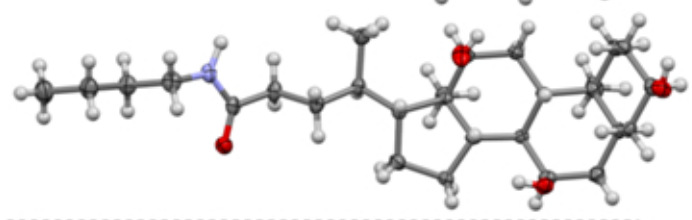

(g)

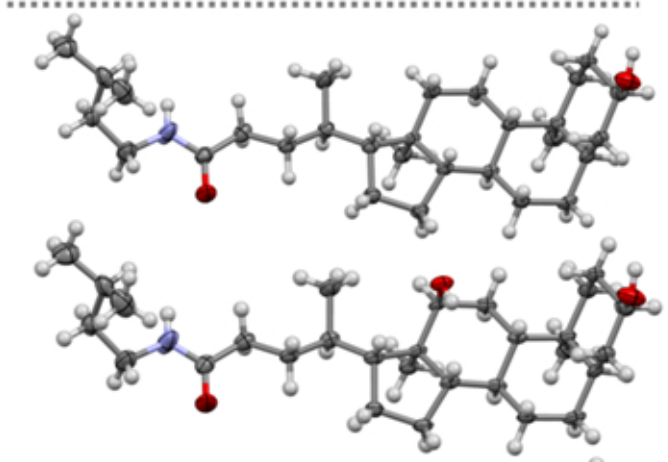

(i)

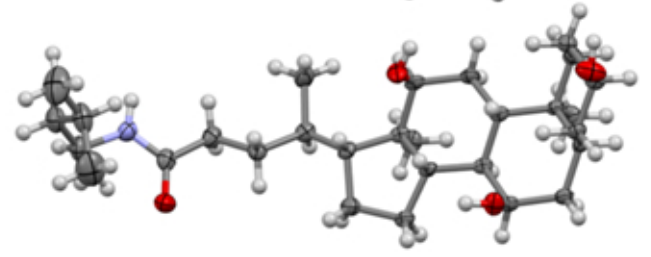

Figure 1. The X-ray crystal structures of (a) $N$-propyllithocholamide, LCA1, (b) $\mathrm{N}$-propyldeoxycholamide, DCA2, (c) N-propylcholamide, CA3, (d) Nbutyllithocholamide, LCA4, (e) $\mathrm{N}$-butyldeoxycholamide, DCA5, (f) $\mathrm{N}$ butylcholamide, CA6, (g) N-iso-pentyllithocholamide, LCA7, (h) N-isopentyldeoxycholamide, DCA8, and (i) $\mathrm{N}$-iso-pentylcholamide, CA9, with thermal ellipsoids at $50 \%$ probability level. 

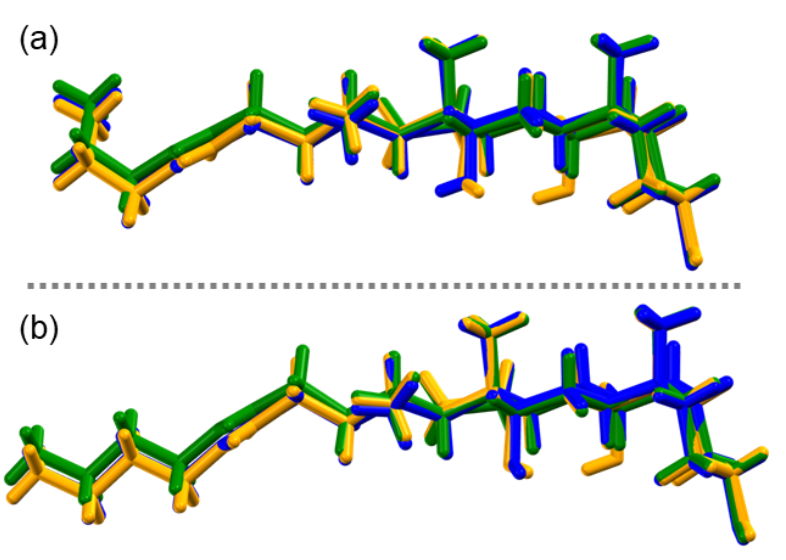

(c)

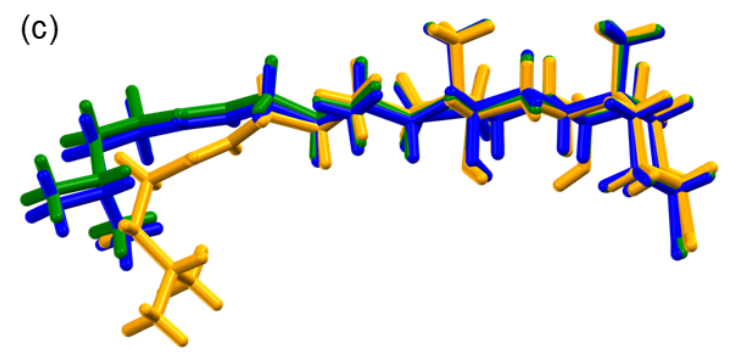

Figure 2. The overlay of the X-ray crystal structures of (a) LCA1, DCA2, and CA3, (b) LCA4, DCA5, and CA6, and (c) LCA7, DCA8, and CA9 shown in capped stick model. Color codes: green (LCA1, LCA4, LCA7), blue (DCA2 DCA5, DCA8), and gold (CA3, CA6, CA9).

vored in aromatic solvents, which is commonly observed for bile acid derivatives. ${ }^{30-33,35-37}$ Furthermore, the gels of the lithocholic acid derivatives LCA1, LCA4, and LCA7 as well as those of the cholic acid derivatives CA3, CA6, and CA9 were thixotropic by nature similar to the gels formed by the ethyl amide derivatives reported previously by us. ${ }^{37}$

Because the formation of the bilayered structures, involving the functional groups in the head (hydroxyl groups) and tail (carboxylic acid groups or their derivatives) of the steroidal backbone, is typical for bile acid derivatives in the solid state, ${ }^{39-41}$ it is reasonable to assume that similar structures exist also in the semi-solid or gel-states. In the case of CA and its derivatives the inter-bilayered interactions are reinforced by hydrogen bonds between the hydroxyl groups at positions $7 \alpha$ and $12 \alpha$ (Table S6). Thus the interstices between the bilayers formed up by the lipophilic $\beta$-faces of the steroidal backbones create suitable environments for the entrapment of aromatic solvent molecules. The LCA derivatives lack hydroxyl groups on the steroidal $\alpha$-face, and are thus relatively lipophilic both on $\alpha$ - and $\beta$-sides. This property favors the entrapment of the aromatic solvent molecules. These structural features account for the tendency of CA and LCA derivatives to form supramolecular gels particularly in aromatic solvents. The DCA derivatives, which bear only one hydroxyl group on the $\alpha$-side of the steroidal skeleton, manifest a different polarity profile. In addition, their mutual orientation is altered (Figures S21b and S22c), which prevents the formation of favorable space for entrapment of solvent molecules and thus disfavors supramolecular gel formation.
Table 1. Gelation test results at $1 \%(\mathrm{w} / \mathrm{v})$ for compounds 1-9.

\begin{tabular}{|c|c|c|c|c|c|c|}
\hline Solvent & LCA1 & CA3 & LCA4 & CA6 & LCA7 & CA9 \\
\hline Benzene & NG & PG & G & NG & $\begin{array}{l}\text { G, } \\
\text { PG }\end{array}$ & G \\
\hline Toluene & NG & G- & G & NG & G- & G \\
\hline Ethylbenzene & NG & NG & PG & NG & $\begin{array}{c}\text { G,G- } \\
\text { PG }\end{array}$ & G \\
\hline o-Xylene & PG & NG & G- & G- & G- & $\mathbf{G}$ \\
\hline$m$-Xylene & NG & NG & G & NG & G & $\mathbf{G}$ \\
\hline$p$-Xylene & G & NG & G & NG & G & G- \\
\hline tert-Butylbenzene & NG & NG & NG & NG & G- & $P G$ \\
\hline Cumene & G-, G & NG & G & NG & G & $\begin{array}{l}\text { G-, } \\
\text { PG }\end{array}$ \\
\hline Chlorobenzene & G & NG & G- & NG & G- & NG \\
\hline Anisole & $\begin{array}{l}\mathbf{G}, \\
\mathrm{PG}\end{array}$ & G & G & $\begin{array}{l}\text { G- } \\
\text { G }\end{array}$ & $\begin{array}{c}\text { PG, } \\
\text { G- }\end{array}$ & $\mathbf{G}$ \\
\hline 1,4-Dioxane & G- & G- & G & NG & $\begin{array}{l}\text { G-, } \\
\text { PG }\end{array}$ & PG \\
\hline Acetonitrile & NG & NG & NG & NG & $\begin{array}{l}\text { G-, } \\
\text { PG }\end{array}$ & NG \\
\hline Carbontetrachloride & $\begin{array}{l}\text { G-, } \\
\text { PG }\end{array}$ & NG & PG & NG & NG & NG \\
\hline Ethyl acetate & $\begin{array}{l}\text { G-, } \\
\text { PG }\end{array}$ & NG & NG & NG & NG & NG \\
\hline
\end{tabular}

G = gel with appr. 0-5\% free solvent, G- = gel with appr. 5-20\% free solvent, $\mathrm{PG}=$ gel with appr. $50 \%$ free solvent, $\mathrm{NG}=$ no gel.

\section{Morphology}

The bile acid derivatives typically form gels consisting of differently organized fibres or of spherical assemblies. ${ }^{30-33,35-37}$ The derivatives LCA1, LCA4, and LCA7 formed gels with flat fibres in chlorobenzene (Figures $3 a-c)$. The width of the fibres in the case of compounds LCA1 and LCA4 was approximately 600-800 $\mathrm{nm}$ and the length approximately $40-50 \mu \mathrm{m}$. Compound LCA7 formed clearly thicker (up to $1.6 \mu \mathrm{m}$ ) and longer (200 $\mu \mathrm{m}$ ) fibres. When the gelator concentration was increased from $1 \%$ to $2 \%(w / v)$, the fibres formed fan-shaped bundles. Similar fanshaped bundles were observed previously within the $1 \%$ hydrogels of LCA ethyl amide. ${ }^{37}$ Interestingly, compounds LCA1 and LCA7 formed hollow nanotubes in ethyl acetate, as can be seen in Figure S3. The nanotubes of compound LCA1 were approximately $390 \mu \mathrm{m}$ long and $30 \mu \mathrm{m}$ in diameter, whereas the flat fibres co-existing with the tubes were approximately $60 \mu \mathrm{m}$ long and $950 \mathrm{~nm}$ wide, respectively. The nanotubes were clearly shorter and thinner in the case of compound LCA7, for which the length varied between $12 \mu \mathrm{m}$ and $32 \mu \mathrm{m}$ and the width between $700 \mathrm{~nm}$ and $3.3 \mu \mathrm{m}$.

The non-gel-forming amides DCA2, DCA5, and DCA8 showed clearly crystalline nature. Compound DCA2 formed a crystal with wood-like surface (Figure $3 d$ ), whereas rods with frayed ends were seen in the case of compound DCA5 (Figure 3e). Compound DCA8 possessed larger entities, which consisted of individual rods (Figure $3 \mathrm{f}$ ). The largest assembly was approximately $19 \mu \mathrm{m}$ long and $9 \mu \mathrm{m}$ wide. The single rods were non-uniform in size; their lengths varied from $250 \mathrm{~nm}$ to $1 \mu \mathrm{m}$, whereas they were approximately $230 \mathrm{~nm}$ wide. Together with the 
entities consisting of rods extremely small spherical assemblies (1.8-3.3 $\mu \mathrm{m}$ in diameter) were observed in the case of compound DCA8.

The amides CA3, CA6, and CA9, for one, formed spherical assemblies, which coexisted with fibres. The assemblies of the propyl amide derivative CA3 were spherical both in $1 \%$ and $2 \%$ chlorobenzene gels (Figure $3 \mathrm{~g}$ ). The $1 \%$ gel consisted of spheres of 1.1-1.45 $\mu \mathrm{m}$ in diameter (Figure S1c), whereas in the $2 \%$ gel the spheres were more versatile in size. The $1 \%$ chlorobenzene gel of the butyl amide derivative CA6 contained some crystalline material (Figure S1d). The crystals were rectangular in shape, and their sizes varied greatly; thickness varying between 21-67 $\mu \mathrm{m}$ and length between $40-230 \mu \mathrm{m}$, respectively. In the $2 \%$ gel some of the crystals had further assembled in spherical structures (Figure $3 \mathrm{~h}$ ). The $1 \%$ chlorobenzene gel of the iso-pentyl derivative CA9 (Figure S4c) also consisted of spherical assemblies, whose diameters were considerably larger $(120 \mu \mathrm{m})$ than those detected in the gel formed by compound CA3 and the surface had a folded structure. The $2 \%$ gel of compound CA9 possessed an extensively folded surface (Figure 3i).

Based on the SEM images an obvious morphological difference between the gel-forming LCA and CA derivatives and the non-gel-forming DCA derivatives can be observed. The gelforming derivatives possess fibrous and spherical structures, whereas the non-gel-forming derivatives form clearly crystalline assemblies.

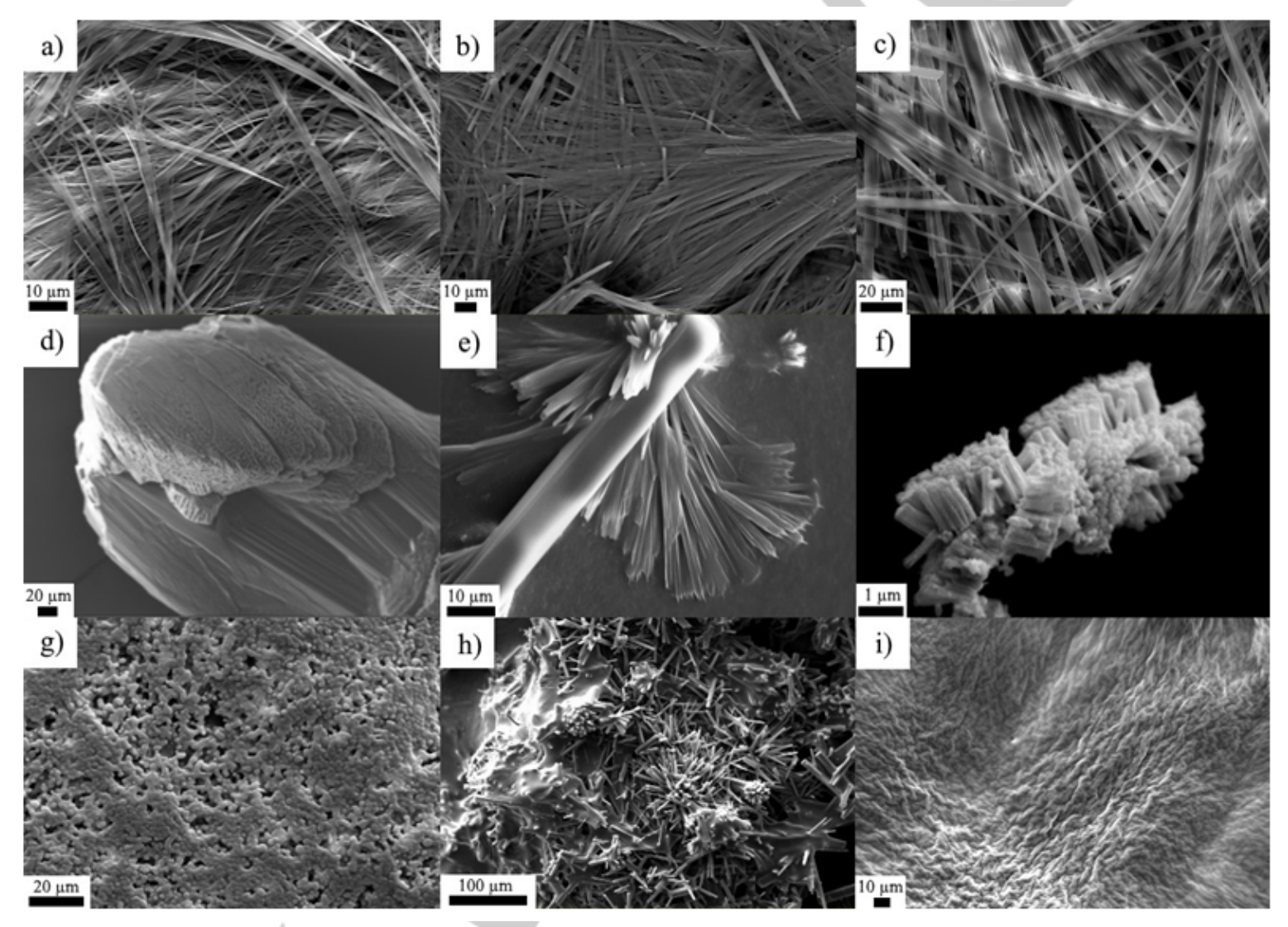

Figure 3. a) $2 \%$ (w/v) chlorobenzene gel of compound LCA1, b) $2 \%$ (w/v) chlorobenzene gel of compound LCA4, c) $2 \%$ (w/v) chlorobenzene gel of compound LCA7, d) $2 \%$ (w/v) chlorobenzene solution of compound DCA2, e) $2 \%$ (w/v) chlorobenzene solution of compound DCA5, f) $2 \%$ (w/v) chlorobenzene solution of compound DCA8, g) $2 \%(\mathrm{w} / \mathrm{v})$ chlorobenzene gel of compound CA3, h) $2 \%(\mathrm{w} / \mathrm{v})$ chlorobenzene gel of compound CA6, and i) $2 \%$ (w/v) chlorobenzene gel of compound CA9.

\section{${ }^{13} \mathrm{C}$ CPMAS NMR}

For the ${ }^{13} \mathrm{C}$ CPMAS NMR measurements, $2 \%(\mathrm{w} / \mathrm{v})$ gel samples of compounds LCA1, CA3, LCA4, CA6, and CA9 in chlorobenzene were prepared. Despite numerous efforts, for compound LCA7 a reasonable $\mathrm{S} / \mathrm{N}$ ratio was not reached by using a concentration of $2 \%(w / v)$, which is why the concentration was increased to $4 \%(\mathrm{w} / \mathrm{v})$. The hot solution containing the compound in question was quickly pipetted into a rotor. The crystalline samples of compounds LCA1, CA3, LCA4, CA6, and CA9 were prepared by recrystallizing the compounds in acetonitrile, and that of LCA7 in DMF to maintain consistency with the single crystal $X$-ray analyses. The crystalline samples were dried under vacuum before the measurements. The gel samples were spun at a rate of $4 \mathrm{kHz}$ and the crystalline ones at $10 \mathrm{kHz}$. The possibility of melting of the gel due to rotation was taken into 
account by using a slower spinning speed. Furthermore, the phase of the sample was ascertained to be a gel by visual inspection immediately after the measurement.

As can be seen from Figure 4 , the ${ }^{13} \mathrm{C}$ CPMAS NMR spectra of the derivatives LCA1, LCA4, and LCA7 measured from the crystalline materials corresponding to the $\mathrm{X}$-ray crystal structures (Figure 1 and Figures $4 \mathrm{a}, \mathrm{c}$, and $\mathrm{e}$ ) and from the chlorobenzene gels (Figures $4 b, d$, and f) are similar to each other. The same applies for the other gel-forming series, the derivatives CA3, CA6, and CA9 (Figures S23-S25) as well. This suggests that the chemical environments and intermolecular interactions in the solid state and in the gel are alike.

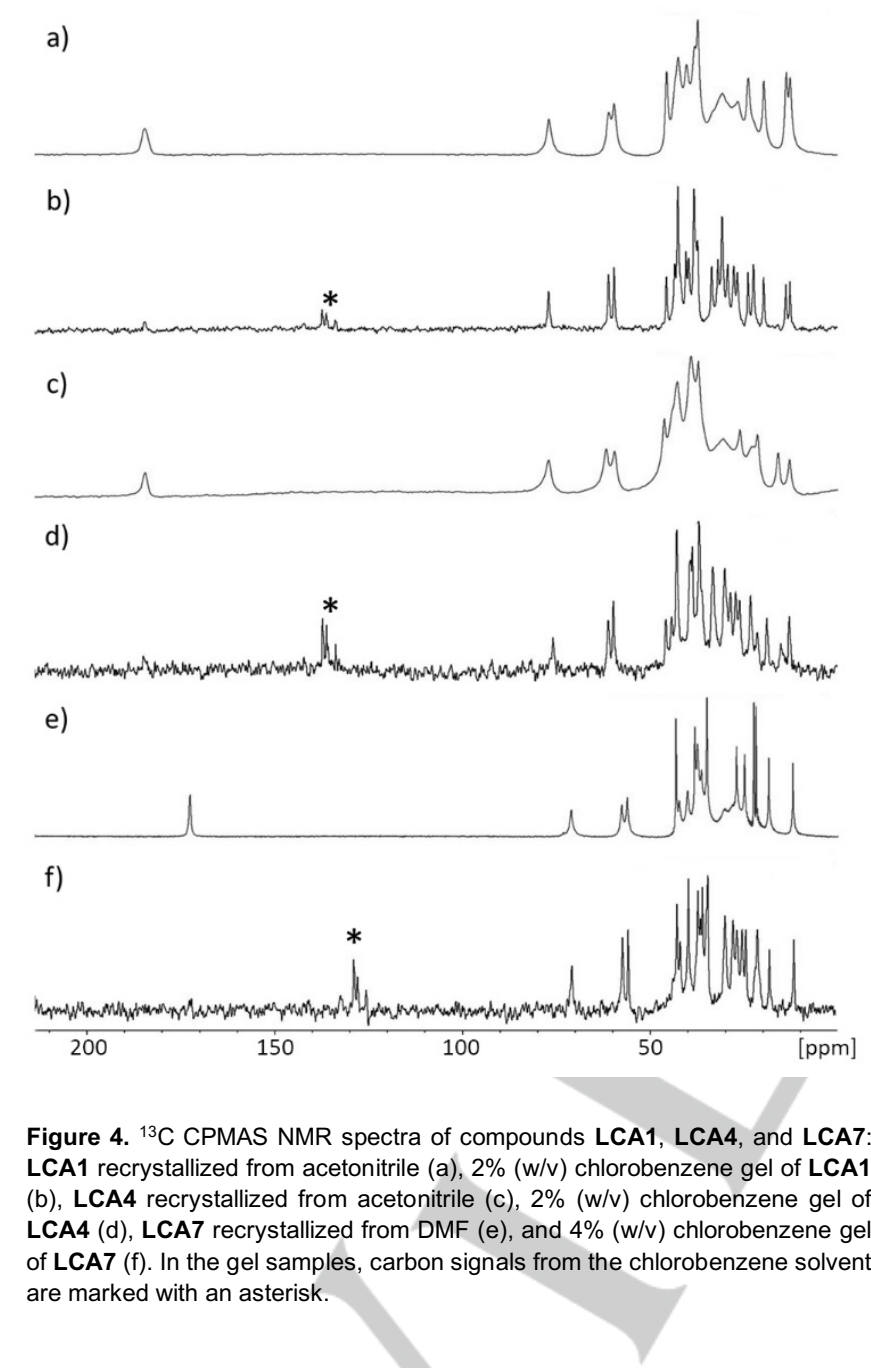

\section{Conclusions}

As a continuation of our systematic studies on the effect of the side chain modification on the gel-forming properties of bile acid derivatives, a detailed study on self-assembly properties of nine bile acid alkyl amides is reported. Based on the results the number of hydroxyl groups attached to the steroidal backbone seems to play a major role in gelation, although the nature of the aliphatic side chain has an impact on the gelation abilities as well. Of the 50 gel systems formed, 35 consisted of LCA and 15 of CA derivatives, whereas DCA derivatives did not form any gels. The intermediate polarity profile on the $\alpha$-side of the DCA derivatives seems to prevent favourable interactions for supramolecular gel formation. The gels of LCA and CA derivatives were formed mostly in aromatic solvents exhibiting typical fibrous or spherical morphologies. The ${ }^{13} \mathrm{C}$ CPMAS NMR spectra measured from the crystalline materials corresponding to the $\mathrm{X}$-ray crystal structures and from the chlorobenzene gels of LCA and CA derivatives are similar to each other indicating similar chemical environments and intermolecular interactions in the crystalline state and in the gels. When used with caution the correlation between single crystal Xray crystallography and solid-state NMR may provide additional insight for inspecting the structure of the supramolecular gels.

\section{Experimental Section}

Details of the syntheses, compound characterizations, and gelation property studies are given in the Electronic Supporting Information.

\section{Acknowledgements}

Ellen and Artturi Nyyssönen Foundation (R.K.), the Academy of Finland (R.P., grant no. 298817), and the University of Jyväskylä are acknowledged for financial support. The authors are grateful to Lab. Tech. H. Salo for SEM studies, Lab. Eng. E. Haapaniemi for liquid state NMR spectroscopy, and Spec. Lab. Tech. J. Lind for mass spectrometry. B.Sc. Sonja Into, B.Sc. Sasu Jaakkola, Mr. Karri Björklund, and Mr. Aleksi Tiusanen are thanked for their contributions to the synthetic work.

Keywords: bile acid amides - X-ray crystallography supramolecular gels $\cdot$ intermolecular interactions $\cdot$ CPMAS NMR

\section{Literature}

[1] P. Terech, R.G. Weiss, Chem. Rev., 1997, 97, 3133-3160.

[2] R.G. Weiss, P. Terech (Eds.), Molecular Gels: Materials with Self-Assembled Fibrillar Networks, Springer, Dordrecht, 2006.

[3] J.W. Steed, Chem. Commun., 2011, 47, 1379-1383.

[4] J.R. Hiscock, F. Piana, M.R. Sambrook, N.J. Wells, A.J. Clark, J.C. Vincent, et al., Chem. Commun., 2013, 49, 9119-9121.

[5] S.M.N. Simões, F. Veiga, J.J. Torres-Labandeira, A.C.F. Ribeiro, A. Concheiro, C. Alvarez-Lorenzo, Macromol. Biosci., 2013, 13, 723-734.

[6] A. Ajayaghosh, V.K. Praveen, Acc. Chem. Res., 2007, 40, 644-656.

[7] C. Rizzo, R. Arrigo, N. T. Dintcheva, G. Gallo, F. Giannici, R. Noto, A. Sutera, P. Vitale, F. D'Anna, Chem. Eur. J., 2017, 23 , 16297-16311. 
[8] S. Marullo, C. Rizzo, N. T. Dintcheva, F. Giannici, F. D’Anna, J. Colloid Interface Sci., 2018, 517, 182-193.

[9] C. Rizzo, F. Arcudi, L. Dordevic, N. T. Dintcheva, R. Noto, F. D'Anna, M. Prato, ACS Nano, 2018, 12, 1296-1305.

[10] E. Ostuni, P. Kamaras, R.G. Weiss, Angew. Chem. Int. Ed. Engl., 1996, 35, 1324-1326,.

[11] D.J. Abdallah, S.A. Sirchio, R.G. Weiss, Langmuir, 2000, 16, 7558-7561.

[12] D.R. Trivedi, A. Ballabh, P. Dastidar, B. Ganguly, Chem. Eur. J., 2004, 10, 5311-5322.

[13] M. George, G. Tan, V.T. John, R.G. Weiss, Chemistry, 2005, 11, 3243-3254.

[14] D.R. Trivedi, P. Dastidar, Chem. Mater., 2006, 18, 14701478.

[15] A. Ballabh, D.R. Trivedi, P. Dastidar, Chem. Mater. 2006, 18, 3795-3800.

[16] D.R. Trivedi, P. Dastidar, Cryst. Growth Des., 2006, 6, 21142121.

[17] M.-O.M. Piepenbrock, G.O. Lloyd, N. Clarke, J.W. Steed, Chem. Commun., 2008, 2644-2646.

[18] A. Ballabh, T.K. Adalder, P. Dastidar, Cryst. Growth Des. 2008, 8, 4144-4149.

[19] P. Sahoo, N.N. Adarsh, G.E. Chacko, S.R. Raghavan, V.G. Puranik, P. Dastidar, Langmuir, 2009, 25, 8742-8750.

[20] U.K. Das, D.R. Trivedi, N.N. Adarsh, P. Dastidar, J. Org. Chem., 2009, 74, 7111-7121.

[21] J. Chen, J.W. Kampf, A.J. McNeil, Langmuir, 2010, 26, 13076-13080.

[22] J. Gao, S. Wu, T.J. Emge, M.A. Rogers, CrystEngComm, 2013, 15, 4507-4515.

[23] A. Enhsen, W. Kramer, G. Wess, Drug Discov. Today, 1998, 3, 409-418.

[24] E. Sievänen, Molecules, 2007, 12, 1859-1889.

[25] D.M. Small, in The Bile Acids Chemistry, Physiology, and Metabolism, P.P. Nair, D. Kritchevsky, Eds., Plenum Press New York, 1971, 249-356.

[26] S. Mukhopadhyay, U. Maitra, Curr. Sci., 2004, 87, 1666-1683. [27] A.P. Davis, Molecules, 2007, 12, 2106-2122.

[28] Nonappa, U. Maitra, Org. Biomol. Chem., 2008, 6, 657-669.

[29] V. Noponen, S. Bhat, E. Sievänen, E. Kolehmainen, Mater. Sci. Eng. C, 2008, 28, 1144-1148.

[30] V. Noponen, M. Lahtinen, A. Valkonen, H. Salo, E. Kolehmainen, E. Sievänen, Soft Matter, 2010, 6, 3789-3796.

[31] M. Löfman, J. Koivukorpi, V. Noponen, H. Salo, E. Sievänen, J. Colloid Interface Sci., 2011, 360, 633-44.

[32] V. Noponen, H. Belt, M. Lahtinen, A. Valkonen, H. Salo, J. Ulrichová, A. Galandáková, E. Sievänen, Steroids, 2012, 77,

193-203.

[33] V. Noponen, A. Valkonen, M. Lahtinen, H. Salo, E. Sievänen, Supramol. Chem., 2013, 25, 133-145.

[34] V. Noponen, K. Toikkanen, E. Kalenius, R. Kuosmanen, H. Salo, E. Sievänen, Steroids, 2015, 97, 54-61.

[35] M. Löfman, M. Lahtinen, M. Pettersson, E. Sievänen, Coll. Surf. A, 2015, 474, 18-28.

[36] M. Löfman, M. Lahtinen, K. Rissanen, E. Sievänen, J. Colloid Interface Sci., 2015, 438, 77-86.
[37] R. Kuosmanen, R. Puttreddy, R.-M. Willman, I. Äijäläinen, A. Galandáková, J. Ulrichová, H. Salo, K. Rissanen, E. Sievänen, Steroids, 2016, 108, 7-16.

[38] S. Bergström, A. Norman, Acta Chem. Scand., 1953, 7, 1126-1127.

[39] Y. Hishikawa, R. Watanabe, K. Sada, M. Miyata, Chirality, 1998, 10, 600-618.

[40] K. Nakano, K. Sada, Y. Kurozumi, M. Miyata, Chem. Eur. J., 2001, 7, 209-220.

[41] N. Yoswathananont, K. Sada, K. Nakano, K. Aburaya, M. Shigesato, Y. Hishikawa, K. Tani, N. Tohnai, M. Miyata, Eur. J. Org. Chem., 2005, 5330-5338.

[42] M. A. Spackman, D. Jayatilaka, CrystEngComm, 2009, 11, 19-32.

[43] M. A. Spackman, J. J. McKinnon, CrystEngComm, 2002, 4, 378-392.

[44] J. J. McKinnon, D. Jayatilaka, M. A. Spackman, Chem. Commun., 2007, 3814-3816

[45] J. J. McKinnon, M. A. Spackman, A. S. Mitchell, Acta Crystallogr. Sect. B, 2004, 60, 627-668. 
WILEY-VCH

\section{Entry for the Table of Contents}

\section{FULL PAPER}
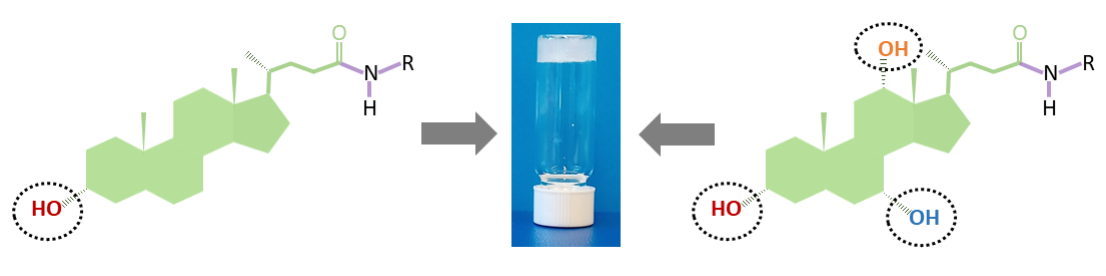

Riikka Kuosmanen, Rakesh Puttreddy, Kari Rissanen*, and Elina Sievänen*

Page No. - Page No.

Systematic Modulation of the

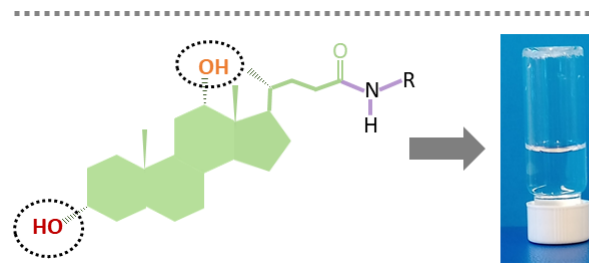
Supramolecular Gelation Properties of Bile Acid Alkyl Amides

A detailed study on the self-assembly properties of nine bile acid acid alkyl amide-based low-molecular weight gelators resulted in 50 gel systems, 35 of which were based on lithocholic acid and 15 on cholic acid derivatives. Deoxycholic acid derivatives, however, did not form any gels. Gelation commenced primarily in aromatic solvents and the gels manifested typical fibrous or spherical morphologies. The ${ }^{13} \mathrm{C}$ CPMAS NMR spectra measured from the crystalline materials and the corresponding organogels were analogous, suggesting that the chemical environments and consequently the intermolecular interactions in the organogels and in the crystalline state are similar. The single crystal $X$-ray structures of all nine bile acid amide derivatives revealed similar molecular conformations in the solid state giving insights into the possible intermolecular interactions in the gel state. 